\title{
Letter to the editor on "Stents and surgical interventions in the palliation of gastric outlet obstruction: a systematic review"
}

We read with interest the paper, "Stents and surgical interventions in the palliation of gastric outlet obstruction: a systematic review" by Minata MK et al, which appeared in Endoscopy International Open (2016; 4: E1158-1170) [1]. The Authors should be congratulated for an extensive and careful review.

In recent studies, we prospectively analyzed the clinical outcomes of $72 \mathrm{pa}$ tients [2,3] and we came to similar conclusions. We have abandoned the use of covered stents. Distal migration of a covered stent can lead to serious consequences and a stent rarely can be retrieved endoscopically [4].

Endoscopic stenting offers many advantages in comparison to surgery: shorter hospital stay, faster return to oral intake, a less invasive procedure. However, life expectance may be longer than 1 year in some patients with malignant gastric outlet obstruction, particularly those with distal gastric cancer or gastric obstruction from metastatic disease.

In this selected group of patients, food obstruction is common. The reason for it in rare cases derives from tumor ingrowth within the stent; in the majority of patients, food obstruction is secondary to dismotility of the pyloric region. The dismotility depends on many factors, including nerve infiltration by the tumor. Food obstruction is not easily diagnosed. The stomach can enlarge significantly before vomiting occurs. Stom- ach dilation can lead to nausea, discomfort, and dyspnea, symptoms that easily can be attributed to the cancer itself.

For all these reasons, patients who have endoscopic stenting in this clinical setting should have a very careful follow-up with repeated endoscopies and computed tomography scan. This careful follow-up may not be well tolerated by a patient whose general condition is slowly deteriorating or for his or her family.

Laparoscopic surgery can be performed with minimal discomfort for patients and it should be seriously considered in patients whose conditions are generally acceptable. Before such a procedure, the patient and family should be consulted and all positive and negative aspects of the surgery should be thoroughly explained, leaving them to choose the preferred treatment.

\section{Competing interests}

None

The authors

Antonietta Lamazza, Enrico Fiori, Antonio V Sterpetti

Isituto Pietro Valdoni, University of Rome-

Sapienza, Italy

\section{Corresponding author}

Antonio V Sterpetti, MD, FACS, FRCS Viale del Policlinico 00167 Rome, Italy Fax: +0039-6-49972245

antonio.sterpetti@uniroma1.it

\section{References}

[1] Minata MK, Bernardo WM, Rocha RS et al. Endosc Int Open 2016; 4: E1158-E1170

[2] Fiori E, Lamazza A, Demasi E et al. Endoscopic stenting for gastric outlet obstruction in patients with unresectable antropyloric cancerSystematic review of the literature and final results of a prospective study. The point of view of a surgical group. Am J Surg 2013; 206: 210-217

[3] Fiori E, Sterpetti AV, De Cesare A et al. Factors leading to improved results for endoscopic stenting for metastastic antropyloric adenocarcinoma: A comparison with gastrojejunostomy. J Gastrointest Surg 2016; 20: 1802 - 1806

[4] Kim CG, Choi I], Lee JY et al. Covered versus uncovered self-expandable metallic stents for palliation of malignant pyloric obstruction in gastric cancer patients: a randomized prospective study. Gastrointest Endosc 2010; 72: 25-32

\section{Bibliography}

DOI http://dx.doi.org/10.1055/s-0043-112496

Endoscopy International Open 2017; 05: E652

(c) Georg Thieme Verlag KG

Stuttgart · New York

ISSN 2364-3722

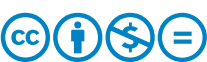

